\title{
Capsule Commentary on Richman et al., Colorectal Cancer Screening in the Era of the Affordable Care Act
}

\author{
Ilana Graetz, PhD \\ Department of Preventive Medicine, University of Tennessee Health Science Center, Memphis, TN, USA.
}

J Gen Intern Med 31(3):325

DOI: $10.1007 / \mathrm{s} 11606-015-3519-8$

(c) Society of General Internal Medicine 2015

$\mathrm{T}$ he Affordable Care Act (ACA) included provisions that eliminated cost-sharing for preventive services recommended by the United States Preventive Services Task Force. In this issue of JGIM, Richland et al. present a timely assessment of how these changes in cost-sharing impacted colorectal cancer screening rates for Medicare beneficiaries. ${ }^{1}$ Using four years of self-reported data, the authors found that overall, the rate of colorectal screening has not changed. Still, they did find a modest but statistically significant increase in the screening rate among those with Medicare only (i.e., no private insurance) and those with income $<125 \%$ of the federal poverty level.

Although the ultimate goal of the ACA provisions is to increase use of evidence-based preventive care, they can't work unless patients understand their plan benefit structure. The authors note a recent survey conducted by the Kaiser Family Foundation in 2014, which found that only $43 \%$ of Americans were aware that cost-sharing had been eliminated for these preventive services. ${ }^{2}$ It is likely that at the time of the Richland study, which used data through 2012, even fewer beneficiaries understood these cost-sharing exemptions. Limited consumer understanding of benefit likely limits the effectiveness of these types of policies in achieving their desired effect.

Previous surveys have found that consumers in commercial health plans with similar cost-sharing exemptions for preventive services had limited knowledge of which services were subject to cost-sharing and frequently reported avoiding free preventive services care because of cost. ${ }^{3,4}$ When designing policies to promote use of certain services, it is important for policy makers to consider the trade-off between plan complexity and potential consumer confusion over benefits. The added complexity of exemptions can result in more confusion and misunderstanding over cost-sharing for all services. Policies that use differential cost-sharing by service should combine these changes with effective communication about plan benefits. To minimize potential confusion, the ACA did require that consumers receive a summary of benefits and coverage that is consistent across plans and ultimately easier for patients to understand. Nonetheless, results by Richland et al. suggest that more effective education and consumer decision support may be needed.

Conflict of Interest: The author has no conflicts of interest with this article.

Corresponding Author: Ilana Graetz, PhD; Department of Preventive MedicineUniversity of Tennessee Health Science Center, Memphis, TN, USA (e-mail: igraetz@uthsc.edu).

\section{REFERENCES}

1. Richman I, Asch S, Bhattacharya J, Owens D. Colorectal cancer screening in the era of the affordable care act. J Gen Intern Med. DOI: 10.1007/ s11606-015-3504-2.

2. Hamel L, Firth J, Brodie M. Kaiser Health Tracking Poll: March 2014 2014. http://kff.org/health-reform/poll-finding/kaiser-health-trackingpoll-march-2014/. Accessed 2/24/2015 2015.

3. Reed ME, Graetz I, Fung V, Newhouse JP, Hsu J. In consumer-directed health plans, a majority of patients were unaware of free or low-cost preventive care. Health Aff (Project Hope). 2012;31(12):2641-2648.

4. Reed M, Fung V, Price M, et al. High-deductible health insurance plans: efforts to sharpen a blunt instrument. Health Aff (Project Hope). 2009;28(4):1145-1154.

This comment refers to the article available at: http://dx.doi.org/10.1007/ s11606-015-3504-2.

Published online September 30, 2015 